\title{
The mass balance of the Greenland ice sheet: sensitivity to climate change as revealed by energy-balance modelling
}

\section{J. Oerlemans}

\author{
(Institute of Meteorology and Oceanography, University of Utrecht, \\ Princetonplein 5, 3584 Utrecht, The Netherlands)
}

Received 22 September 1990 Revised manuscript accepted 19 October 1990

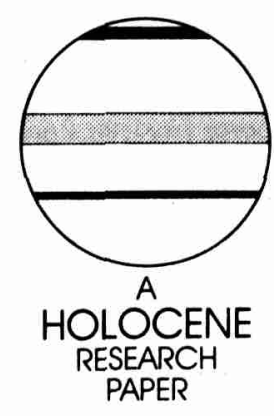

PAPER

\begin{abstract}
The sensitivity of the mass balance of the Greenland ice sheet to climate change is studied with an energy-balance model of the ice/snow surface, applied at $200 \mathrm{~m}$ elevation intervals for four characteristic regions of the ice sheet. Solar radiation, longwave radiation, turbulent heat fluxes and refreezing of melt water in the snow pack are treated separately. The daily cycle is fully resolved.

For the climatology chosen as input (mainly from work by A. Ohmura), the mean specific balance produced by the model is $0.079 \mathrm{~m} / \mathrm{yr}$ (water equivalent). Comparing this with the total accumulation, $0.313 \mathrm{~m} / \mathrm{yr}$, it is obvious that the ablation is quite large. However, a $1 \mathrm{~K}$ decrease of the imposed annual mean temperature leads to a specific balance of $0.147 \mathrm{~m} / \mathrm{yr}$, a $1 \mathrm{~K}$ increase to $0.003 \mathrm{~m} / \mathrm{yr}$. Because of this large sensitivity, it appears that the present state of balance cannot be determined from climatological data.

The calculations show that changes in the earth's orbit during the Holocene must have had a significant effect on the mean specific balance of the Greenland ice sheet. The balance was smaller than today during most of the last 10000 years, probably by as much as $0.05 \mathrm{~m} / \mathrm{yr}$. Further experimentation showed that the changes in the specific balance can be related to changes in summer insolation. The difference between a typical high latitude minimum in insolation (e.g., $25000 \mathrm{BP}$ ) and a high latitude maximum in insolation (e.g., $10000 \mathrm{BP}$ ) is equivalent to the effect of a $2 \mathrm{~K}$ difference in annual mean temperature. So when considering mass balance changes for a particular glacier during the Holocene, it is important to consider the orbital and climatic effects separately, because they may work in the same or in the opposite direction, depending on the location.

In a warmer world, ablation will increase, but this will be compensated to some extent by increased snowfall. For a uniform warming of $1 \mathbf{K}$, and including a precipitation rate proportional to maximum possible atmospheric water content, the model predicts a contribution to sea level rise of $0.27 \mathrm{~mm} / \mathrm{yr}$.
\end{abstract}

Key words: Energy-balance modelling, Greenland ice sheet, mass balance, climate change, orbital effects, Holocene.

\section{Introduction}

During the last decade, the interest in the effects of a possible greenhouse warming on sea level has greatly stimulated the study of the major ice sheets. It has been recognised that changes in land ice volume are likely to occur even for relatively small climatic perturbations (e.g. Meier, 1984; NAP, 1985; Robin, 1986). However, in recent assessments it has also become clear that very basic questions about the Greenland and Antarctic ice sheets cannot be answered. For instance, it is unknown whether the ice sheets are in balance with the present-day climatic conditions (Warrick and Oerlemans, 1990). In fact, a look at characteristic time scales for adjustment of velocity and thermal fields in ice sheets (e.g. Whillans, 1981) makes clear that such a balance is unlikely to exist. The ice sheets must still be slowly reacting to the last glacial-interglacial transition. Recent numerical experimentation supports this view (e.g. Dahl-Jenssen and Johnsen, 1986; Huybrechts and Oerlemans, 1988).

The response of ice sheets to climatic forcing is complicated, and numerical models are needed to quantify the interaction between ice flow, ice temperature field, isostatic adjustment of the underlying bed, etc. Still, no matter how accurate such a model is, the value of a particular simulation depends critically on the formulation of the surface mass balance. In many studies, imposing climatic change to glaciers 
and ice sheets has been done by moving an equilibrium line up and down and keep the balance profile fixed, or by assuming that perturbations of the mass balance are independent of height. Such an approach is to some extent suggested by measurements, as year-to-year variations in the mass balance of a glacier certainly have a height-independent component. Still, it is not so obvious that year-to-year variability forms the proper basis for deriving the sensitivity of glacier mass balance to climatic change on longer time scales. In view of this, a more process-oriented approach is certainly useful.

Especially when ablation plays an important role, as is the case for the Greenland ice sheet, this involves a consideration of the energy balance of the snow/ice surface, either in a highly parameterized way like the degree-day method (setting the ablation proportional to the sum of positive daily temperatures), or by a more explicit treatment of the components of the surface energy budget. The degree-daymethod has been applied to ablation measurements in southwest Greenland by Braithwaite and collaborators (e.g. Braithwaite and Olesen, 1989). Pioneering work on the energy-balance approach was done by Ambach (e.g. Ambach, 1963, 1979a, 1979b). Application of a more universal energy balance model to derive the mass balance of the entire Greenland ice sheet has recently been described in Oerlemans et al. (199x).

The present paper forms an extension of this work. On the basis of a large number of numerical experiments, in which boundary conditions and model constants are varied, three questions will be discussed, namely,

i) Is it possible to calculate the present surface balance of the Greenland ice sheet from climatological data?

ii) What are the most critical meteorological/ glaciological processes that determine the sensitivity of the balance to climatic change?

iii) Did significant changes in the surface balance occur during the Holocene?

Estimates of the balance of the Greenland ice sheet found in the literature differ widely, as illustrated by Table I. When going back to the original papers it becomes clear that all are first-order estimates, not obtained by a systematic statistical method. The early estimates only give an idea of the characteristic mass turnover of the ice sheet, but certainly not of the sign of the net balance. Note that in the table ablation ranges from $35 \%$ of the total accumulation (Reeh, 1985) to as much as $66 \%$ (Bauer, 1967). The accumulation figure appears as more reliable than the partition of the mass loss over ablation and calving. In a recent assessment of all massbalance data combined with precipitation measurements at meteorological stations (which are all at or very close to the coast) Ohmura and Reeh (1990) arrive at a figure of $535 \mathrm{~km}^{3}$ of ice per year for the accumulation, and this is likely to be accurate to $10 \%$ or so. However, up to the present date, the problem of how much ice is lost by calving and how much by ablation, and of the sign of the net balance remains.

The surface balance at a particular site depends on the energy balance of the surface and the amount of precipitation. Irrespective of the precise treatment of these factors in a model, external parameters need to be prescribed. Naturally, three sets of parameters can be distinguished (see Figure 1). The first set describes the large-scale climatic conditions and could consist of annual temperature, seasonal temperature range, precipitation, cloudiness, temperature lapse rate, etc. The second set describes a possible direct influence on the energy balance of the surface. Variations in solar luminosity or the orbital parameters belong in this class. The third set must give the local geometric conditions (surface elevation, slope and aspect, possible shading effects).

Expressing the actual energy balance of the surface in terms of the external parameters and solar forcing involves meteorological theory. Much of this is of an empirical nature, like for example the relation between cloudiness and global radiation. It is outside the scope of the present paper to discuss this in detail, but a brief description of the various approximations is given the second section. For the sake of completeness, details are then provided in the Appendix.

\section{The mass balance model}

The mass balance is obtained by integrating the balance equation in time:

$$
M_{s}=\int_{\text {year }}\{\min (0 ;-B / L)+\dot{P}\} d t
$$

$B$ is the energy balance at the surface, $L$ is the latent heat of melt at $273 \mathrm{~K}(334000 \mathrm{~J} / \mathrm{kg}) . P$ is the rate of precipitation falling in solid form. It is assumed that snowfall occurs whenever air temperature is below $2^{\circ} \mathrm{C}$. Precipitation falling as rain, as well as meltwater, is supposed to run off. This is an approximation, as in the cold firn area this will not be generally true. The calculations show, however, that the amount of precipitation falling as rain on the ice sheet is only a few percent of the total. The integration of the mass balance equation is performed with a 15 minute time step, to obtain a satisfactory resolution of the daily cycle. In this paper the discussion focusses on the mean specific balance $M_{s}$, where mean implies averaging over the entire ice sheet and specific

Table 1 The mass budget of the Greenland ice sheet - a listing of estimates found in the literature.

\begin{tabular}{lllll}
\hline source & accumulation & ablation & calving & balance \\
\hline Bader (1961) & +630 & -120 to -270 & -240 & +270 to +120 \\
Benson (1962) & +500 & -272 & -215 & +13 \\
Bauer (1967) & +500 & -330 & -280 & -110 \\
Weidick (1984) & +500 & -295 & -205 & 0 (assumed) \\
Reeh (1985) & +487 & -169 & -318 & 0 (assumed) \\
Ohmura \& Reeh (1990) & +535 & & &
\end{tabular}




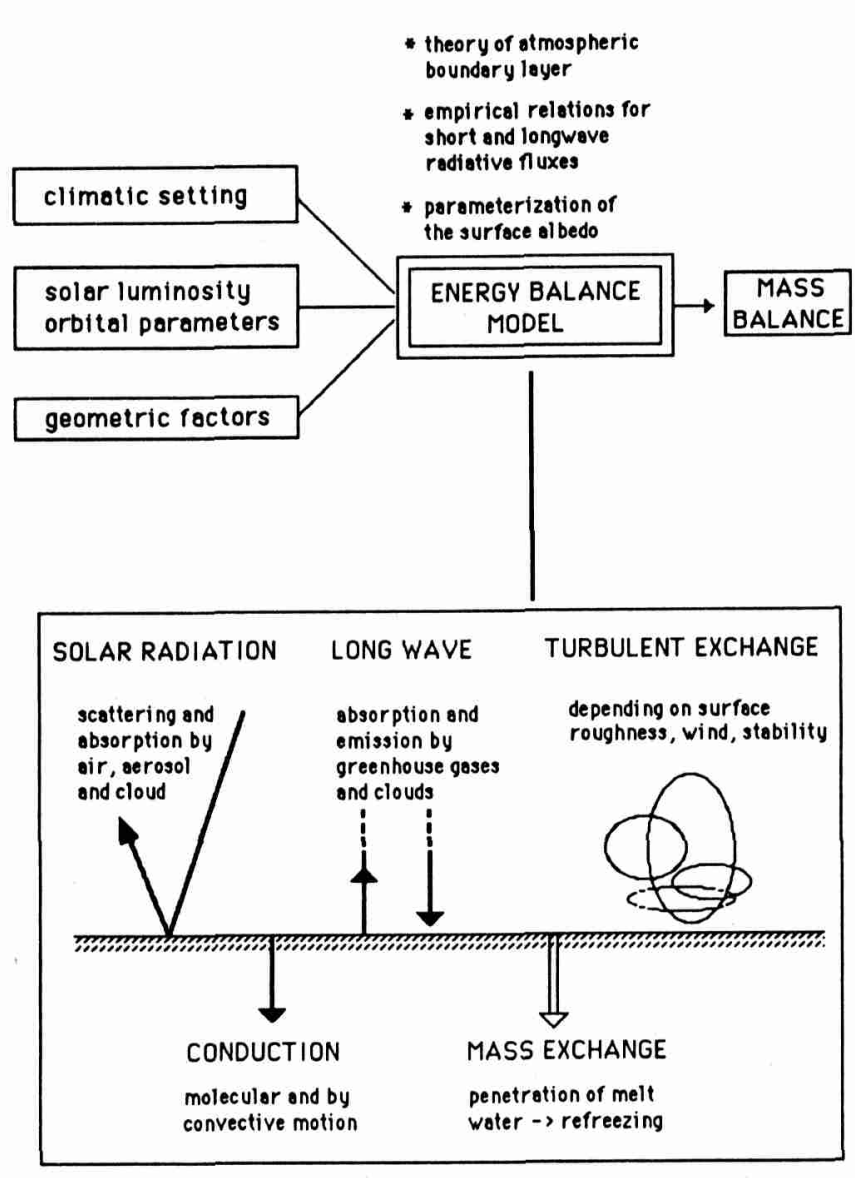

Figure 1 Illustration of the approach to calculate the mass balance of the Greenland ice sheet. Three sets of input parameters are needed, describing the large scale climatic conditions, the extra-terrestrial forcing, and local geometric effects. In the lower panel the various components of the surface energy budget are shown.

refers to unit area. The loss of ice due to calving is not included in the mean specific balance. $M_{s}$ is expressed in metres of water equivalent per year ( $\mathrm{m} / \mathrm{yr}$ in the following).

Processes affecting the surface energy balance are schematically summarized in Figure 1. The relative importance varies strongly from place to place, and from time to time.

(a) Solar radiation. Solar irradiance at the top of the atmosphere is calculated from standard methods (e.g., Walraven, 1978). Attenuation of the solar beam by absorption and scattering is taken care of by simple empirical relations, giving the global radiation at the surface in dependence of solar zenith angle, cloudiness and surface elevation. The surface albedo is an extremely important quantity. The parameterization employed in the model deals with the presence of snow (taking account of snow depth), distance to the equilibrium line and accumulated melt during the ablation season. In this way the albedo is 'internally generated', which is desirable when using an energy balance model to study climate sensitivity. The parameterization is able to reproduce, in a broad sense, the characteristic space and time pattern of surface albedo found on glaciers (Oerlemans, 199x). As the albedo profile is linked to the difference between surface elevation and equilibrium-line altitude (which in turn is calculated by the model after a one year's integration for many elevations), the mass balance model has to be run for three years before the solution becomes really steady.

(b) Terrestrial radiation. The radiation emitted by the surface is directly obtained from the surface temperature, where the emissivity is assumed to be 1 . As the surface cannot exceed the melting point, the maximum amount radiated upwards is $316 \mathrm{~W} / \mathrm{m}^{2}$. The calculation of incoming infrared radiation follows the approach suggested by Kimball et al. (1982). There are two contributions: one from the clear/ sky atmosphere, and one originating at the base of clouds and transmitted in the 8-14 $\mu \mathrm{m}$ band (atmospheric window). Cloud type is not considered, but the height of the cloud base must be provided, as it is used to calculate the cloud base temperature from the prescribed atmospheric temperature lapse rate. So, for a particular location, the terrestrial radiation balance is obtained from three quantities: surface air temperature at screen height, cloudiness and height of cloud base.

(c) Turbulent energy fluxes. The turbulent transfers are taken proportional to the difference between temperature/ humidity at screen height and at the surface. The exchange coefficient is taken the same for the sensible and turbulent heat flux, and does not depend on surface roughness, wind speed and boundary-layer stability. The latter would be possible only when these parameters were locally available. The relative humidity is assumed to be constant (75\%), so only air temperature has to be prescribed for the calculation of the turbulent transfers. Evaporation is calculated as a component in the surface energy balance. However, riming is not taken into account in the present model version.

(d) Refreezing of meltwater. Meltwater penetrating into the snowpack with a temperature below the melting point will refreeze and not run off. This process is dealt with in the model, in such a way that the fraction of meltwater running off increases when the snow/ice temperature approaches the melting point (see Appendix). When the integration is started, the ice temperature is set equal to the annual mean air temperature. This temperature can then only be changed by refreezing meltwater in the beginning of the ablation season. So at higher elevations, where temperatures are lower, more snow has to be melted before the cold layer is heated up and significant runoff may start. The empirical constants involved are chosen such that the result is in line with the findings of Ambach (1963).

Conduction in the snowpack and ice layers is not modelled, as this would require the solution of a fairly complicated diffusion equation to obtain the temperature profile. For the present purpose this was not considered worthwhile, as the energy transfer involved in the refreezing process is much more important at most places. A more detailed discussion on the energy balance of a glacier surface, including a comparison between cases with and without a temperature calculation inside the glacier, can be found in Greuell and Oerlemans (1986).

A model run consists of integrating the mass balance equation for a number of surface elevations (spaced at $200 \mathrm{~m}$ ) for one year, calculating the equilibrium-line altitude from the output by interpolation, make a new integration with the adjusted equilibrium-line altitude, etc., until a steady massbalance profile is obtained. The model version used here needs the following input parameters to calculate one balance profile:

Set 1: annual mean temperature annual temperature range daily temperature range mean atmospheric lapse rate annual march of atmospheric lapse rate annual precipitation as a function of surface elevation 
mean cloudiness and cloud height

Set 2: tilt of earth axis eccentricity of orbit calendar date when earth-sun distance is at minimum

Set 3: surface elevation

slope of the surface

exposure of the surface

Note that both cloudiness and precipitation are assumed to be uniform through the year. This is not realistic, but insufficient data leave no other option. Both the seasonal and daily temperature cycles as well as the seasonal cycle in lapse rate have a sinusoidal shape, determined by the mean and the amplitude.

A typical example of model output is given in Figure 2. In fact it refers to an experiment for average climatic conditions on the Greenland ice sheet (of course there are large variations over Greenland, and this point will be discussed shortly). Shown are the cumulative mass balance, expressed in metre of water equivalent, the surface albedo, and the temperature of the upper snow/ice layer. The curves are for a surface elevation of $300 \mathrm{~m}$ only, i.e. far down in the ablation zone. In the model the transition from accumulation to the ablation season appears quite sharp. To a large extent this can be attributed to the refreezing process, which delays the runoff. The march of the simulated albedo is pronounced and highly asymmetric through the year. In the autumn, when the integration is started, the albedo increases only gradually - a consequence of the small amount of snow falling (for a considerable part of the time, snow occurs in patches rather than a closed cover). The ice/snow temperature, finally, directly reflects the primitive way in which this quantity is handled in the model. As mentioned earlier, a real temperature calculation is not done. What is seen here is the direct effect of refreezing meltwater. Note, however, that the model is able to refreeze more meltwater when annual air temperature is lower, which is realistic.

\section{A calculation for the present climate}

As in Oerlemans et al. (199x), the Greenland ice sheet is divided into four characteristic regions (see Figure 3): the dry north and northeasterly part (region 1), the moist southwesterly part including the southern tip (region 2), the drier and relatively warm part of the west coast between approximately 65 and $69^{\circ} \mathrm{N}$ (region 3) and the moister and colder area along the Baffin Bay (region 4). The regions are not chosen according to drainage basins or groups of drainage basins, but purely on climatological grounds. So they are not separated by ice divides. The input data for these regions are mainly from work by Radok et al. (1982), Ohmura (1987) and Ohmura and Reeh (1990), and are given in the Appendix.

In Figure 3 the calculated mass balance profiles are shown. Calculations were performed for $200 \mathrm{~m}$ elevation intervals (starting at $100 \mathrm{~m}$ ), giving sufficient resolution. There are notable differences among the regions, which are directly related to the precipitation and temperature regime. The smallest mass turnover is found in region 1, the largest in region 2 . The equilibrium-line altitude is generally just below $1000 \mathrm{~m}$, but significantly higher in region 3 . It is quite obvious that region 3 , where most research on glacier mass and energy balance has been done, cannot be considered typical for the Greenland ice sheet. However, the agreement of the mass balance profile with measurements performed in southwest Greenland (e.g. Braithwaite and Olesen, 1984, 1989) gives
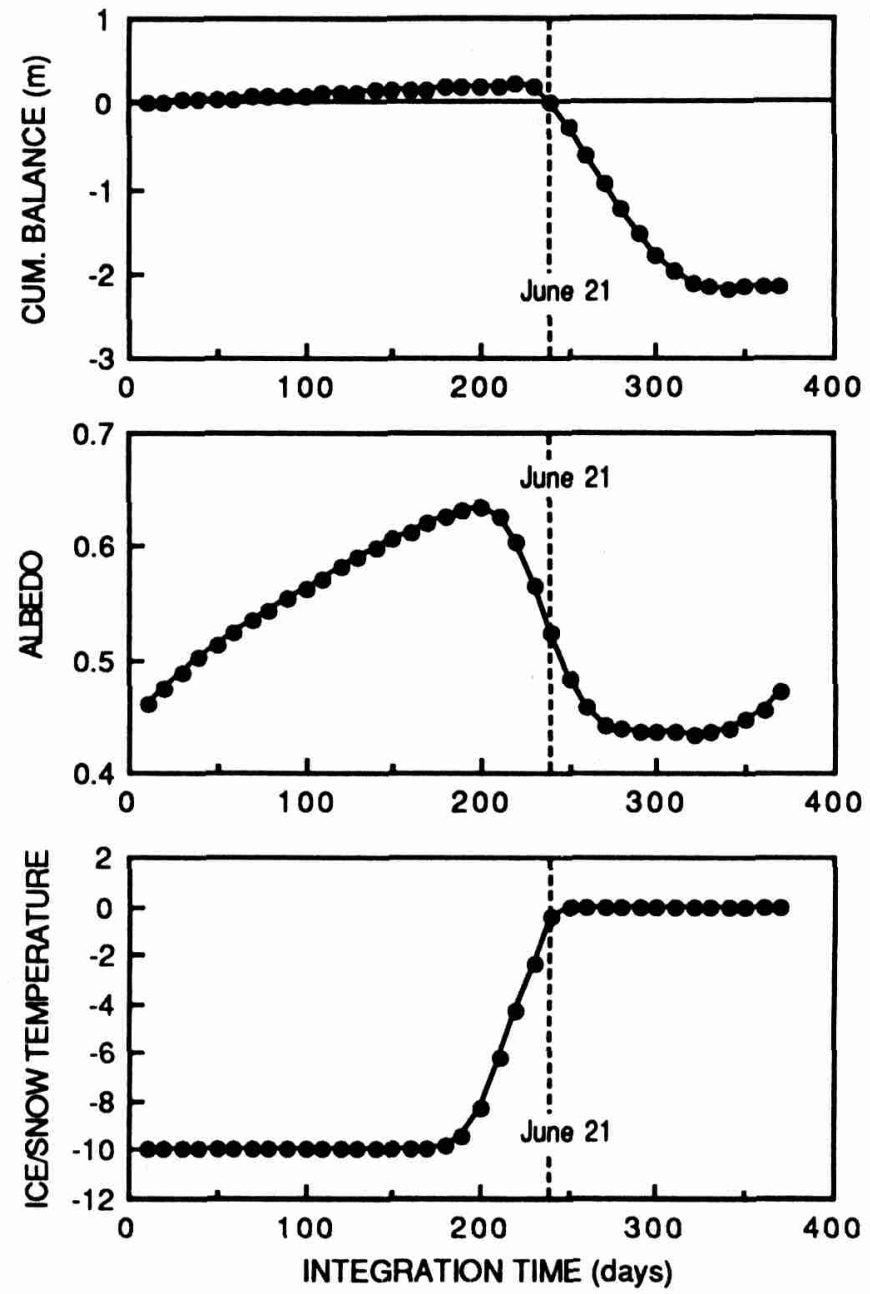

Figure 2 An example of output from a one year's integration. In this case, average climatological conditions for the entire ice sheet were used in a single run. Results shown here are for the grid point at $300 \mathrm{~m}$ above sea level.

confidence in the applicability of the present model.

The total surface balance is obtained by multiplying the balance profiles with the area-elevation distributions. These have been obtained from a map produced at the Geological Survey of Greenland (Weidick, 1971), with some minor modifications. In Figure 4 glacier area, annual precipitation (input to the model) and net mass balance, averaged over the entire ice sheet, are shown as a function of elevation. The mean specific balance thus found in $0.079 \mathrm{~m} / \mathrm{yr}$. As the area of the ice sheet is $1.73 \times 10^{6} \mathrm{~km}^{2}$ (Haeberli et al., 1989), this corresponds to a total water volume of $137 \mathrm{~km}^{3}$. With a mean specific accumulation of $0.313 \mathrm{~m} / \mathrm{yr}\left(541 \mathrm{~km}^{3}\right.$ of total water), the mean ablation thus equals $0.234 \mathrm{~m} / \mathrm{yr}\left(404 \mathrm{~km}^{3}\right.$ of water). In case of equilibrium, the annual discharge by iceberg calving should be equivalent to about $137 \mathrm{~km}^{3}$ of water. Comparing this to Table I makes clear that this deviates substantially from many of the mass balance estimates. According to the present model, the loss of ice due to ablation is much higher than that due to calving. Although, as stated earlier, the numbers found in the literature are uncertain, it appears that the present calculation yields too much ablation.

To make a proper interpretation of this result it is absolutely necessary to consider the sensitivity to some input parameters, notably temperature. If the annual mean surface 


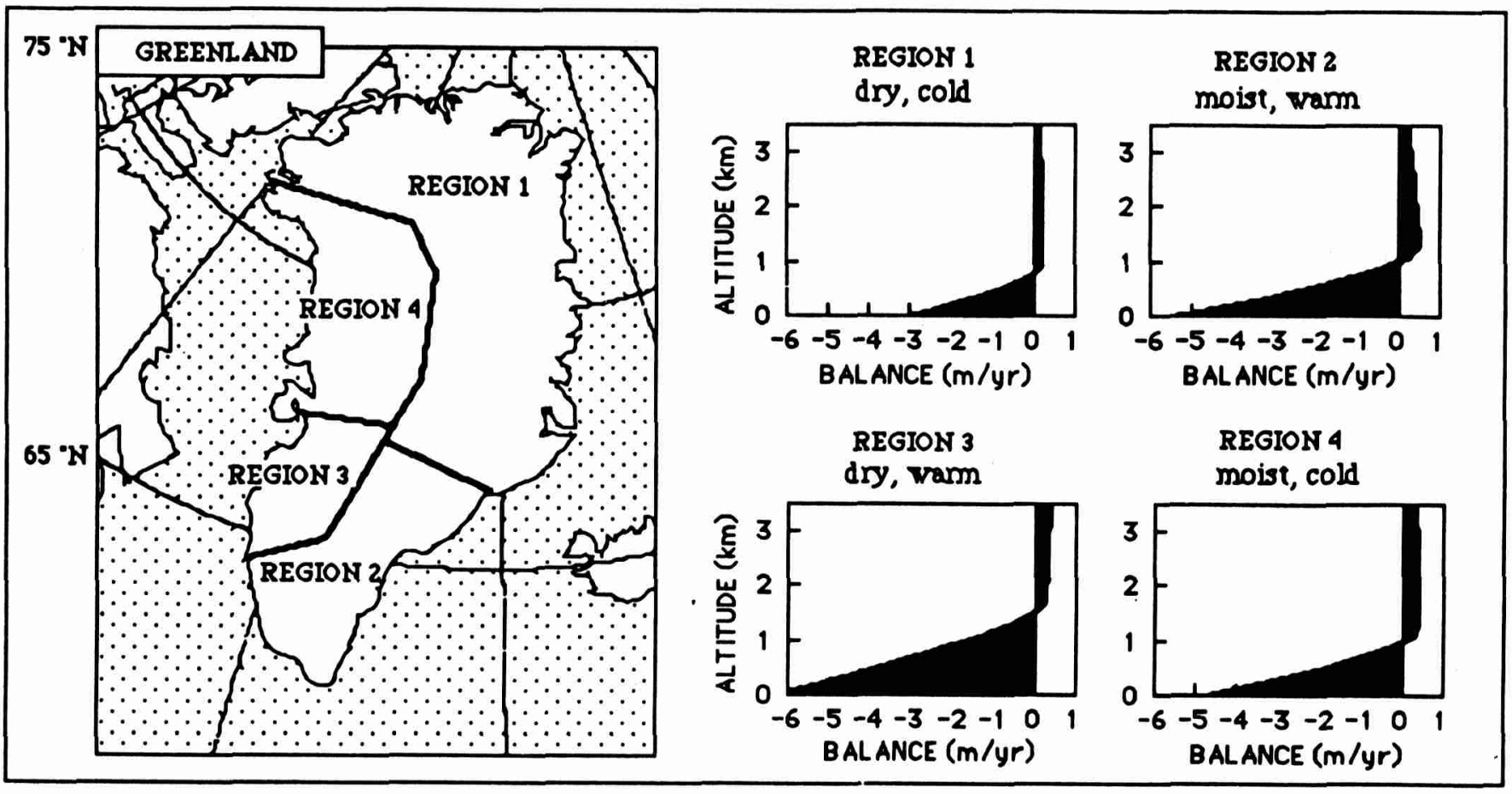

Figure 3 Calculated profiles of the specific balance for four characteristic regions. The largest ablation occurs in region 3 , the largest accumulation in region 2 .

temperature is increased uniformly by $1 \mathrm{~K}$, the net specific balance becomes $0.0026 \mathrm{~m} / \mathrm{yr}$, while for a $1 \mathrm{~K}$ decrease a value of $0.1474 \mathrm{~m} / \mathrm{yr}$ is found. So the sensitivity is quite large. As the mean annual air temperature on Greenland is certainly not known to an accuracy better than $1 \mathrm{~K}$, one must conclude that it is impossible to obtain the present state of balance from climatological input data. The use of a mass balance model, no matter how sophisticated, will probably not solve the problem of the current state of balance of the ice sheet. This does not make the mass balance model useless, as it remains the best tool to study the sensitivity of the mass balance to all kinds of climatic perturbations. However, a reference state then has to be chosen in an arbitrary way, that is, in line with the general concensus. In the following discussion on parameter sensitivity, the $-1 \mathrm{~K}$ case mentioned above has been selected as the reference against which results are considered. The corresponding annual mean temperature, reduced to sea level and averaged over the entire Greenland region, is $-8^{\circ} \mathrm{C}$.
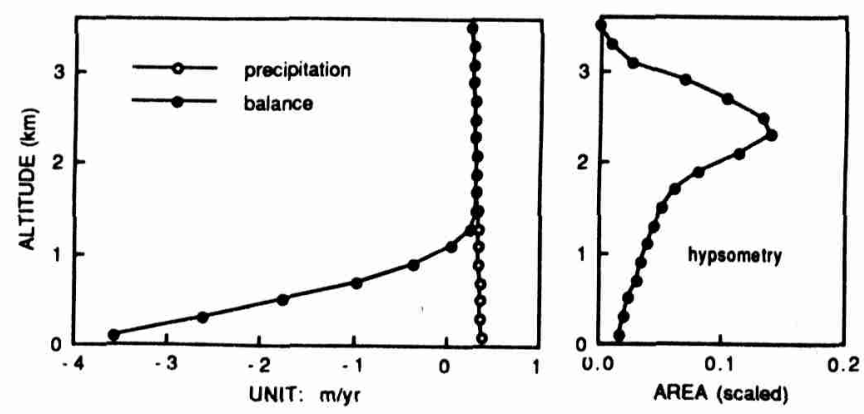

Figure 4 Specific balance as a function of elevation for the reference case. The profile is the average calculated from four runs for the different regions. Note that this reference case is for a $1 \mathrm{~K}$ lower mean temperature that the results in Figure 3 (see text). The areaelevation distribution has an arbitrary scale.

\section{Parameter sensitivity}

A large number of runs was carried out to see the dependence of the specific balance on temperature, annual temperature range, albedo, etc. The results are summarized in Figure 5. For all experiments shown in this figure, only one model parameter was changed at a time. The effects on the mass balance are not necessarily additive, however, as nonlinear effects (in particular the albedo feedback) may come into play.

As already mentioned above, the sensitivity of the specific balance to air temperature is large: the ablation increases by about $50 \%$. This is due to higher ablation rates as well as a significant lengthening of the ablation season. As the melting process only occurs in spring and summer, and then mainly during the warmest part of the day, it is not surprising that both the annual and the daily temperature range have a significant effect on the balance. The albedo feedback becomes clearly visible, in the experiment where the annual precipitation has been increased uniformly by $10 \%$. The direct effect is an increase in the specific balance of $0.031 \mathrm{~m} / \mathrm{yr}$ (ignoring the part of the precipitation which falls as rain and is supposed to run off, which is really very small), but the model calculates a change of $0.037 \mathrm{~m} / \mathrm{yr}$. The difference of $0.006 \mathrm{~m} / \mathrm{yr}$ is due to the longer lasting snowcover in the ablation zone.

As discussed extensively by Ambach (1974), the effect of clouds on the energy balance of the surface is twofold. First of all, increasing cloud cover reflects more sunlight back to space and thus leads to a reduced energy balance. At the same time, the longwave balance increases because of increasing counter radiation. The net effect depends on the surface albedo. For a low surface albedo the effect on the short wave balance dominates and more clouds lead to a reduction of the energy balance. For high surface albedo (typically well beyond the equilibrium line), on the other hand, more clouds cause the energy balance to increase. So 
when averaged over the entire Greenland ice sheet, one expects opposing effects in the ablation and accumulation zones. It appears that the changes in the ablation zone are more important: the net result of a 0.1 increase in cloud cover is to increase the specific balance by $0.066 \mathrm{~m} / \mathrm{yr}$. It must be stressed here that the treatment of clouds in the present model is very simple. No differentation is made between high and low cloud, which generally have very different optical properties. The dependence of the mass balance on cloud cover can only be considered as a first indication.

As the amount of absorbed solar radiation directly depends on the albedo, one expects a significant sensititivy here. Indeed, a uniform lowering of the albedo by 0.05 decreases the balance by about the same amount as a $1 \mathrm{~K}$ rise in the annual mean temperature. This change of the albedo is really small.

The last two bars in Figure 5 show the effect of halving or doubling the coefficient for turbulent exchange $(C$, see Appendix). In both cases the model predicts a lower specific balance, which is an unexpected behaviour. Some additional runs were carried out to understand this result, and the outcome is shown in Figure 6. When considering the balance as a function of $C$, it appears that a maximum occurs for $C$ $=10 \mathrm{~W} /\left(\mathrm{m}^{2} \mathrm{~K}\right)$. If there would be no sensible and latent heat flux at all $(C=0)$, the mean specific balance would be negative. The explanation for this can be appreciated from Figure $6 \mathrm{~b}$, where the balance profiles are shown for $C=0$, $15,30 \mathrm{~W} /\left(\mathrm{m}^{2} \mathrm{~K}\right)$. Apparently, the role of the turbulent heat flux is to cool the surface in the higher parts of the ice sheet, and to heat the lower parts. Without any turbulent heat flux, the equilibrium line would go up by as much as $800 \mathrm{~m}$ ! A very large value of $C$ has little effect on the melting higher up, because it is already almost zero, but it further enhances melting in the lower ablation zone and thus leads to a decreasing mean specific balance of the ice sheet.

\section{Specific mean balance and temperature change}

It has been suggested that accumulation on the Greenland ice sheet will increase for higher temperatures. The physical argument is the relation between air temperature and saturation mixing ratio. Analysis of accumulation rates from deep ice cores (Reeh et al., 1979) lends some support to this view. The complicating factor is the atmospheric circulation. A change of annual mean temperature, or annual temperature range, will generally be associated with a change in the climatic regime. A slight shift in the circulation pattern over

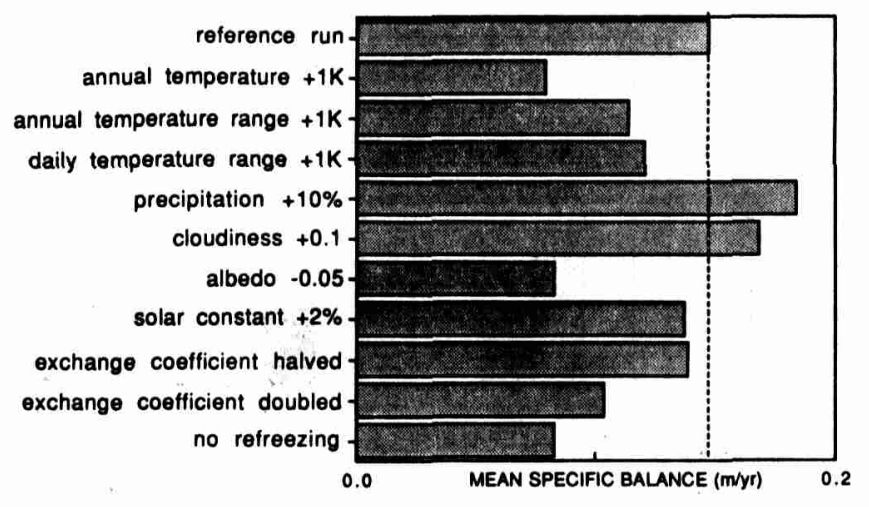

Figure 5 Results of the sensitivity analysis. Only one input parameter has been changed at a time. the Greenland ice sheet and its surroundings can easily change precipitation rates by the same amount as the temperature changes (Keen, 1982). Still, it is worthwhile to investigate the temperature effect, and to see to what extent increased/decreased accumulation can offset the simultaneously occurring increase/decrease of ablation.

In relating precipitation and temperature, one can either use the saturation mixing ratio of the surface air, or take the total amount of water vapour in an atmospheric column. The latter approach gives a somewhat lower sensitivity as mean air temperature is lower. In Oerlemans and Van der Veen $(1984$, p. 140) a graph is shown that gives amount of water in an atmospheric column as a function of sea-level temperature and surface elevation. It was obtained by integrating model atmospheres over the vertical. For typical Greenland conditions, the change in precipitation due to a different moisture holding capacity of the air then turns out to be about $4 \% / \mathrm{K}$.

A number of runs were carried out with this temperatureprecipitation relation included. The result is plotted in Figure 7. As expected, a temperature range exists where the mean specific balances reaches the highest values. The model further predicts a zero mean specific balance for a temperature increase of $2.3 \mathrm{~K}$ only. Here one should add the uncertainty in the present-day climatology ( $\pm 1 \mathrm{~K}$, say), implying that the temperature increase at which accumulation and runoff balance is very likely to be in the $1.5-3.5 \mathrm{~K}$ range. It should again be stressed, however, that the curve is for
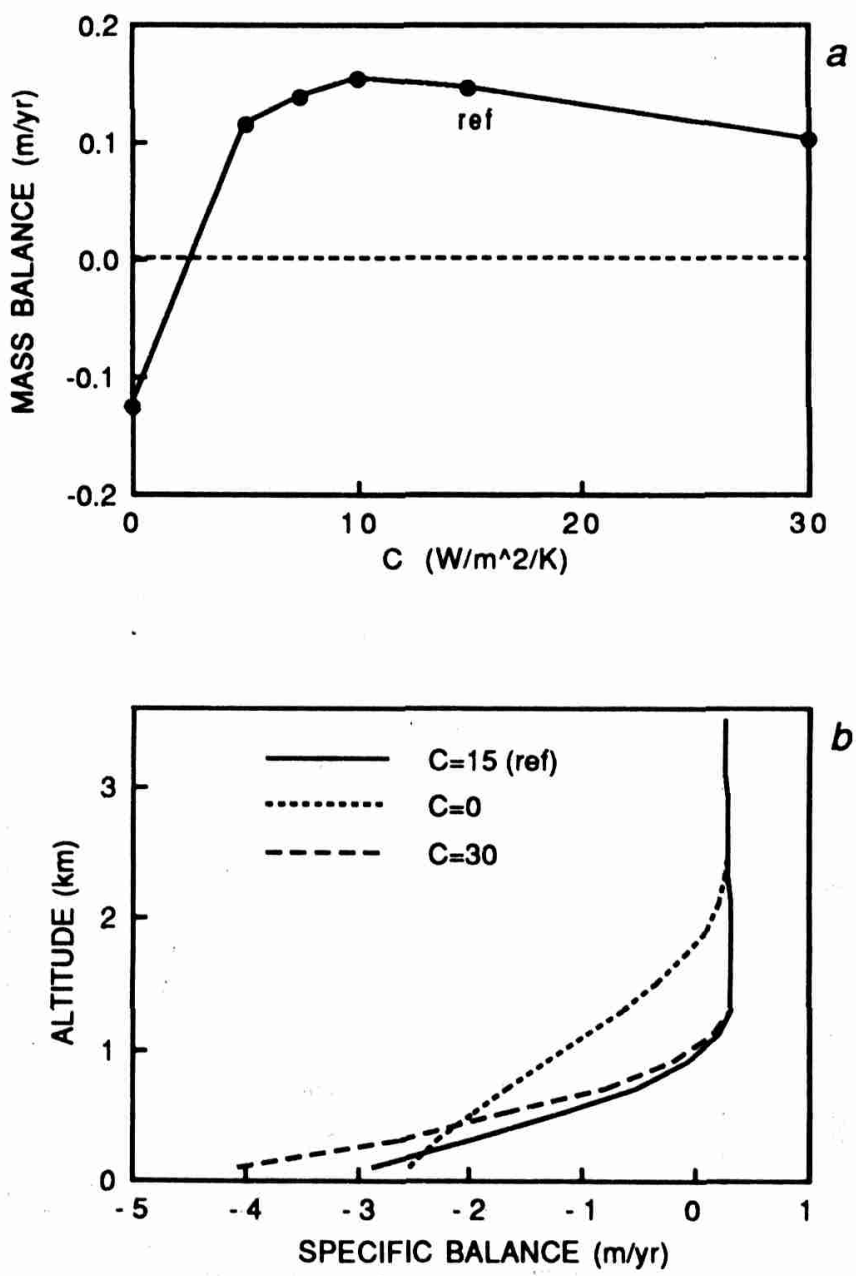

Figure 6 (a) the Mean specific balance in dependence of the turbulent exchange coefficient $C$. (b) The balance profiles for the reference case, no turbulent heat flux $(C=0)$, and a case with doubled exchange. 
unchanged circulation patterns and for a fixed shape of the ice sheet.

To relax the second condition, a dynamic ice sheet model has to be run in conjunction with a mass balance model. This is outside the scope of the present paper, but has been undertaken by other workers (Letréguilly et al., 1991). Nevertheless, a simple analysis can give an idea of the importance of changes in ice sheet geometry. For small perturbations a simple scaling argument can be used to estimate the response of the ice sheet to a changed specific balance. For a continental ice sheet on a flat continent the mean surface elevation ( $=$ ice thickness) $Z$ can be expressed in a characteristic horizontal length scale (e.g., half of the linear dimension, say $W$ ), the mean specific balance $M_{s}$ and an effective flow parameter $\mu$ according to (Van der Veen and Oerlemans, 1984):

$$
Z=\mu^{-1 / 7} M_{s}^{1 / 7} W^{4 / 7}
$$

If we denote a reference state by a subscript $r$, it follows that for small perturbations of the mass balance the change in mean ice thickness can be obtained from (supposing that $W$ does not change):

$$
\frac{Z^{\prime}}{Z_{r}}=\frac{1 M_{s}^{\prime}}{7 M_{s r}}
$$

So, in an absolute sense, the thickness reacts to changes in the mass balance only in a moderate way, a well-known consequence of the strongly nonlinear rheology of ice. According to this equation, the mass balance model yields $Z^{\prime}$ I $Z_{r}=0.089$ for a $1 \mathrm{~K}$ temperature increase. With $Z_{r} \approx 1900 \mathrm{~m}$, it follows that $Z^{\prime}=169 \mathrm{~m}$. This is a large value, as the corresponding change in mean surface temperature would be about $1 \mathrm{~K}$, i.e. of the same order of magnitude as the cause of the ice sheet thinning. So the height - mass balance feedback is positive and strong. For a further analysis of the feedback of ice-sheet geometry on climatically forced massbalance perturbations the present analysis is far too simple. It can only demonstrate the importance.

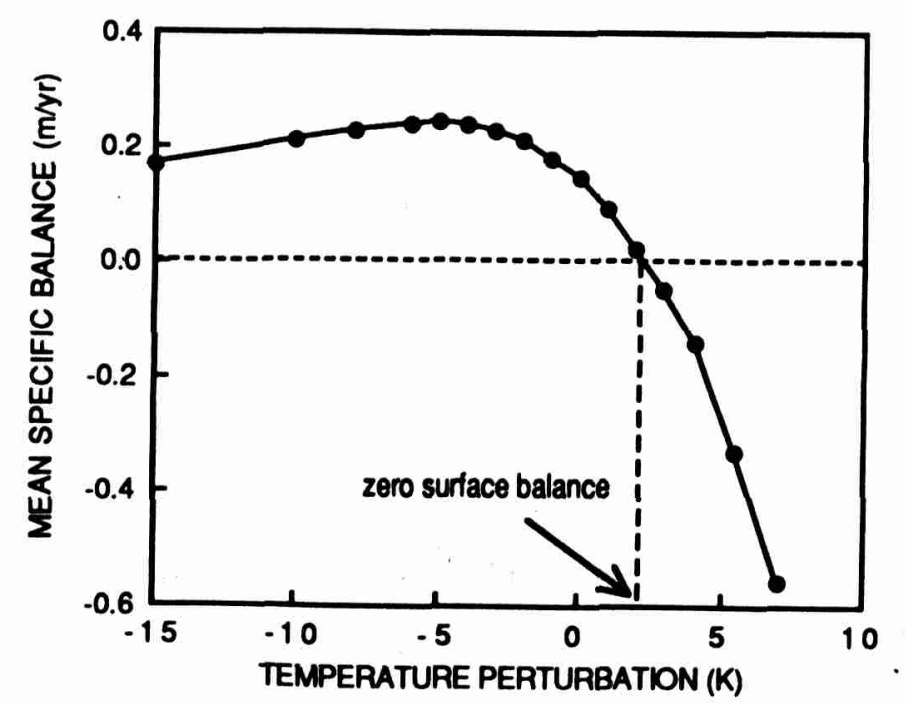

Figure 7 The mean specific balance calculated for a wide range of temperature changes. The effect of temperature on precipitation has been taken into account.

\section{Changes in orbital parameters}

When studying possible changes in the mass balance conditions during the Holocene, a distinction has to be made between the extra-terrestrial forcing (orbital parameters) and a different climatic regime felt by the ice surface [although this regime may have changed itself as a result of different orbital parameters]. In contrast to parameterization schemes where equilibrium-line altitude or mass balance is related to air temperature only, the present approach is able to discriminate between these effects.

Three situations are considered and compared with the present day: $5000 \mathrm{BP}, 10000 \mathrm{BP}$ and $130000 \mathrm{BP}$. In each case, first a basic model run has been made in which the orbital parameters have been adjusted (according to Berger, 1978), but the present-day climatology is used. In a second run, the annual mean and/or annual range of surface temperature has then been changed. Some results are shown in Figure 8.

The different orbit at 5000 BP leads to a small reduction of the mean specific balance, namely $-0.022 \mathrm{~m} / \mathrm{yr}$. Adding conservative estimates of temperature change for the climatic optimum (annual mean temperature $+0.5 \mathrm{~K}$, annual range + $1 \mathrm{~K})$ gives a substantial further lowering of the specific balance. For the 10000 BP case the effect of the orbital parameters is larger, as in that time summer insolation at high northern latitudes was close to a maximum. In view of the fact that the last remains of the Laurentide ice sheet were probably still existing and must have had a cooling effect on the climate in the North American - West Atlantic region (e.g., COHMAP, 1989), the annual temperature was not increased for the 'orbit+climate run', but only the annual range. This roughly doubles the decrease in specific balance. The $130000 \mathrm{BP}$ case, finally, shows the largest orbital effects, as expected. Compared to the $10000 \mathrm{BP}$ case, the 130000 BP case has a similar precessional phase and tilt of the earth's axis, but the eccentricity was significantly larger. Including again a (conservative) estimate of temperature changes for the Eemian interglacial, the mean specific balance turns out to be almost zero (for the present-day ice sheet geometry).

\section{Conclusions}

The energy balance model presented here seems capable of reproducing the characteristic mass balance features of the Greenland ice sheet. Due to the large sensivity to climatalogical input parameters, the model cannot be used to diagnose the present state. A sensitivity test shows that a $1 \mathrm{~K}$ increase

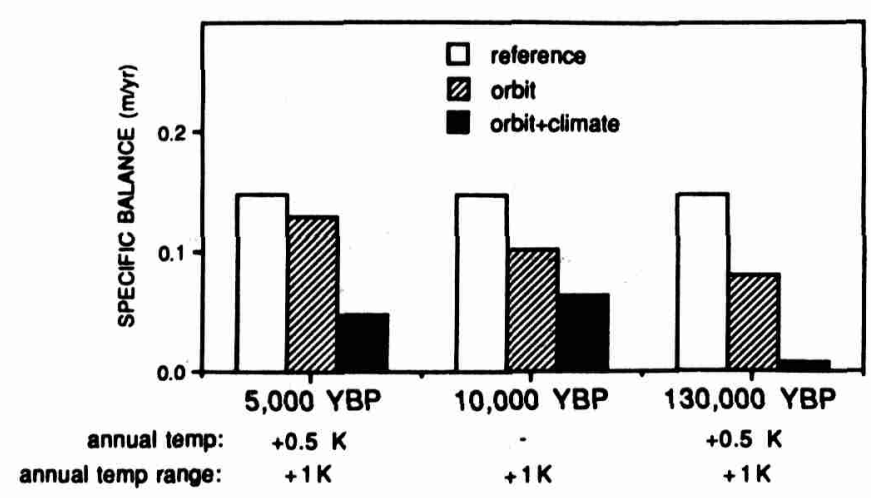

Figure 8 Mean specific balance calculated for some earlier times, but with present-day ice sheet geometry. 
in the annual mean temperature increases the total ablation by about $50 \%$. An effect of similar magnitude occurs for a 0.05 reduction in albedo. Accepting that the imposed annual mean temperature for the Greenland region has an accuracy of $1 \mathrm{~K}$, it follows that the temperature increase making the mean specific balance zero is in the $1.5-3.5 \mathrm{~K}$ range.

The calculations show that changes in the earth's orbit during the Holocene must have had a significant effect on the mean specific balance of the Greenland ice sheet. It appears likely that the balance was smaller than today during most of the last 10000 years, probably by as much as $0.05 \mathrm{~m} / \mathrm{yr}$. The corresponding increase of runoff from the lower ablation zone is between 0.25 and $0.5 \mathrm{~m} / \mathrm{yr}$. This is certainly sufficient to explain the retreat of the ice margin inland from the present location in central West Greenland, as derived from reworked biogenic material found in neoglacial moraines. This retreat probably culminated somewhere between 2000 and $5000 \mathrm{BP}$, with an ice margin $10 \mathrm{~km}$ more inland at many places (Kelly, 1980; Weidick, 1984).

Further experimentation with the mass-balance model showed that the changes in the specific balance can be simply related to changes in summer insolation (averaged over the caloric summer, see Berger, 1978). The difference between a typical high latitude minimum in insolation (e.g., $25000 \mathrm{BP}$ ) and a high latitude maximum in insolation (e.g., $10000 \mathrm{BP}$ ) corresponds to the effect of a $2 \mathrm{~K}$ difference in annual mean temperature. So when considering mass balance changes for a particular glacier during the Holocene, it is important to consider the orbital and climatic effects separately. Depending on the location, these forcing factors may work together or partly compensate each other, so care has to be taken in relating climatic conditions and former equilibrium-line altitudes.

There is ample room for further improvements of the mass balance model presented here. Particular critical points are:

* the surface albedo

* refreezing and superimposed ice

$*$ the turbulent energy fluxes

* the radiation balance and clouds

Further field campaigns in connection with remote sensing studies seems to be required to derive formulations that have a more universal applicability. A further natural extension of the present work would be to apply the mass balance model to a grid covering the entire ice sheet, with variable resolution.

\section{Acknowledgements}

I appreciate the interesting discussions on Greenland mass balance I had with W. Ambach, R. Braithwaite, W. Greuell, $\mathrm{Ph}$. Huybrechts, A. Ohmura and R. van de Wal during the course of this study. Financial support was obtained from the Ministry of Housing, Physical Planning and Environment (The Netherlands), and by the Climate Programme of the European Commission, under contract no. EVUC-0053NL(GDF).

\section{References}

Grønlands Geologiske Undersøgelse Rapport 96, 1-24 pp The Geological Survey of Greenland, Copenhagen.

Kimball, B.A., Idso, S.B. and Aase, J.K. 1982: A model of thermal radiation from partly cloudy and overcast skies. Water Resources Research 18, 931-36.

Letréguilly, A., Huybrechts, Ph. and Reeh, N. 1991: Steady state characteristics of the Greenland ice sheet under different climates. Journal of Glaciology, in press.

Meier, M.F. 1984: Contribution of small glaciers to global sea level. Science 226, 1418-21.

NAP 1985: Glaciers, Ice Sheets and Sea Level: Effect of a $\mathrm{CO}_{2}$ induced Climatic Change. Washington: National Academy Press.

Oerlemans, J. 199x: A model for the surface balance of ice masses: Part I: alpine glaciers. Zeitschrift für Gletscherkunde und Glazialgeologie, submitted.

Oerlemans, J. and van der Veen, C.J. 1984: Ice Sheets and Climate. Reidel, $217 \mathrm{pp}$.

Oerlemans, J., van de Wal, R.S.W. and Conrads, L.A. 199x: A model for the surface balance of ice masses: Part II: application to the Greenland ice sheet. Zeitschrift für Gletscherkunde und Gla. zialgeologie, in press.

Ohmura, A. 1987: New temperature distribution maps for Greenland, Zeitschrift für Gletscherkunde und Glazialgeologie 23, 1-45.

Ohmura, A. and Reeh, N. 1991: New precipitation and accumulation maps for Greenland. Journal of Glaciology, in press.

Radok, U., Barry, R.G., Jenssen, D., Keen, R.A., Kiladis, G.N. and McInnes, B. 1982: Physical Characteristics of the Greenland Ice Sheet.
Boulder: CIRES-Report.

Reeh, N. 1985: Greenland ice sheet mass balance and sea level change. In Glaciers, Ice Sheets and Sea Level: Effects of a $\mathrm{CO}_{2-}$ induced Climatic Change. Washington: National Academy Press, 155-71.

Reeh, N., Clausen, H.B., Gundestrup, N., Johnson, S.J. and Stauffer, B. 1979: Secular trends of accumulation rates at three Greenland stations. Journal of Glaciology 20, 27-30.

Robin, G. deQ. 1986: Changing the sea level. In Bolin, B., Döös, B.R., Jäger, J. and Warrick, R.A., editors, New York: John Wiley \& Sons, 323-59.

Van der Veen, C.J. and Oerlemans, J. 1984: Global thermodynamics of a polar ice sheet. Tellus 36A, 228-35.

Walraven, R. 1978: Calculating the position of the sun. Solar Energy 20, 393-97.

Warrick, R.A. and Oerlemans, J. 1990: Sea level rise. In Climate Change - The IPCC Scientific Assessment, (WMO-UNEP), Cambridge: Cambridge University Press, 257-81.

Weidick, A. 1971: Short explanation to the quaternary map of Greenland. Grønlands Geologiske Undersøgelse. Rapport no. 36, Copenhagen.

- 1984: Review of glacier changes in West Greenland. Zeitschrift für Gletscherkunde und Glazialgeologie 21, 301-309.

Whillans, I.M. 1981: Reaction of the accumulation zone portions of glaciers to climatic change. Journal of Geophysical Research 86 (C5), 4274-82. 


\section{Appendix}

\section{Equations, model constants and input data}

List of symbols

$A_{\Gamma} \quad$ amplitude of annual temperature march of lapse rate $(\mathrm{K} / \mathrm{m})$

$A_{\Theta} \quad$ amplitude of annual temperature cycle (K)

$B$ surface energy balance $\left(\mathrm{W} / \mathrm{m}^{2}\right)$

$c_{p} \quad$ specific heat $(\mathrm{J} /[\mathrm{kg} \mathrm{K}])$

$d \quad$ snow depth (m)

C turbulent exchange coefficient $\left(15 \mathrm{~W} /\left[\mathrm{m}^{2} \mathrm{~K}\right]\right.$ in standard version)

$D \quad$ day number (starting January, 1 )

$D_{o} \quad$ day number when earth-sun distance reaches minimum

$D_{\Theta} \quad$ amplitude of daily temperature march (K)

$e_{a} \quad$ vapour pressure of air at screen height $(\mathrm{Pa})$

$e_{a s} \quad$ saturation vapour pressure over water $(\mathrm{Pa})$

$e_{i c e} \quad$ saturation vapour pressure over ice $(\mathrm{Pa})$

$E$ equilibrium-line altitude (m)

$f$ fraction of black-body function $\Theta_{c l}$ in atmospheric window (8-14 $\mu \mathrm{m})$

$G$ global radiation $\left(\mathrm{W} / \mathrm{m}^{2}\right)$

$h \quad$ surface elevation $(\mathrm{m})$

$h_{c l} \quad$ height of cloud base relative to sea level (m)

$H_{s} \quad$ sensible heat flux $\left(\mathrm{W} / \mathrm{m}^{2}\right)$

$H_{l} \quad$ latent heat flux $\left(\mathrm{W} / \mathrm{m}^{2}\right)$

$H_{\text {ice }}$ heat flux into firn/ice layer $\left(\mathrm{W} / \mathrm{m}^{2}\right)$

$I_{\text {in }} \quad$ incoming terrestrial radiation $\left(\mathrm{W} / \mathrm{m}^{2}\right)$
$I_{\text {out }}$ outgoing terresterial radiation $\left(\mathrm{W} / \mathrm{m}^{2}\right)$

$L \quad$ latent heat of melt $(\mathrm{J} / \mathrm{kg})$

$M_{s} \quad$ mean specific balance $(\mathrm{m} / \mathrm{yr})$

$M_{m} \quad$ accumulated melt during ablation season (m)

$M_{\Gamma} \quad$ annual mean lapse rate $(\mathrm{K} / \mathrm{m})$

$M_{\Theta} \quad$ annual mean temperature at sea level $\left({ }^{\circ} \mathrm{C}\right)$

$n$ cloudiness

$p \quad$ atmospheric surface pressure

$R$ energy available for melting and runoff $\left(\mathrm{W} / \mathrm{m}^{2}\right)$

$S \quad$ solar constant $\left(\mathrm{W} / \mathrm{m}^{2}\right)$

$t \quad$ local solar time in hr $(0-24$, noon $=12)$

$T_{a} \quad$ clear-sky transmissivity for solar radiation (global)

$T_{c} \quad$ effective cloud transmissivity for solar radiation (global)

$P \quad$ annual precipitation (m)

$\mathrm{U}$ relative humidity $(\%)$

$\alpha \quad$ spectrally-averaged surface albedo for global radiation

$\alpha_{b} \quad$ 'background' albedo profile

$\alpha_{s n} \quad$ mean albedo for snow ( 0.75 for standard version)

$\gamma \quad$ solar elevation (degrees)

$\Gamma \quad$ temperature lapse rate $(\mathrm{K} / \mathrm{m})$

$\Theta_{a} \quad$ air temperature (screen height) $\left({ }^{\circ} \mathrm{C}\right)$

$\Theta_{c l}$ temperature of cloud base (K)

$\Theta_{\text {ice }}$ mean temperature of a layer equivalent to $2 \mathrm{~m}$ of solid ice

$\Theta_{s} \quad$ temperature at sea level $\left({ }^{\circ} \mathrm{C}\right)$

$\Theta_{o} \quad$ melting point $(273.16 \mathrm{~K})$
The energy balance

$B=(1-\alpha) G+I_{\text {in }}+I_{\text {out }}+H_{s}+H_{l}$

\section{Surface albedo}

$$
\begin{gathered}
\alpha=\max \left[0.12 ; \alpha_{s n}-\left(\alpha_{s n}-\alpha_{b}\right) \exp (-5 d)-0.015 M_{m}\right] \\
\text { where } \alpha_{b}=0.089 \arctan \{(h-E+400) / 500\}+0.48 \\
\alpha_{s n}=0.75
\end{gathered}
$$

\section{Solar radiation}

$$
G=S T_{a} T_{c} \sin \gamma
$$

$$
\text { where } \begin{aligned}
T_{a} & =(0.79+0.000024 h)\{1-0.009(90-\gamma)\} \\
T_{c} & =1-(0.41-0.000065 h) n-0.37 \mathrm{n}^{2} \\
S & =1353\left\{1+e\left(\cos \left[2 \pi\left(D-D_{o}\right) / 365\right]\right)\right\}
\end{aligned}
$$

\section{Terrestrial radiation}

$$
\begin{aligned}
& I_{\text {in }}=\varepsilon_{a}\left(\Theta_{a}+\Theta_{o}\right)^{4}+\varepsilon_{c l} n f \Theta_{c l}^{4} \\
& \text { where } \varepsilon_{a}=0.7-0.000025 h \\
& f=0.6732+0.00624 \Theta_{c l}-0.914 \times 10^{-5} \Theta_{c l}^{2} \\
& \varepsilon_{c l}=0.75 \\
& \text { temperatures: } \Theta_{a}=\Theta_{s}-\Gamma h[\text { in } C] \\
& \Theta_{c l}=\Theta_{s}-\Gamma h_{c l}+\Theta_{o}[\text { in } K]
\end{aligned}
$$

Turbulent fluxes

$$
\begin{gathered}
H_{s}=C\left(\Theta_{a}-\Theta_{s}\right) \quad H_{l}=0.622 \frac{C L}{c_{p}} \frac{(1-0.01 U)}{p / e_{a s}} \\
\text { where } p=10^{5}(1-0.0001 h) \\
e_{a s}=610.8 \exp \left[19.85\left(1-\Theta_{o} / \Theta_{a}\right)\right]
\end{gathered}
$$

Refreezing of meltwater

$R=B \exp \left(\Theta_{\text {ice }}\right)$

$H_{\text {ice }}=B-R=B\left\{1-\exp \left(\Theta_{\text {ice }}\right)\right\}$

Temperature regime

$\Theta_{a}=\Theta_{s}-\Gamma h$

where $\Theta_{a}=\Theta_{s}-\dot{\Gamma} h$

$\Theta_{s}=M_{\Theta}-A_{\Theta} \cos [2 \pi(D-26) / 365]-D_{\Theta} \cos [2 \pi(t-3) / 24]$

$\Gamma=M_{\Gamma}-A_{\Gamma} \cos [2 \pi(D-26) / 365]$ 


\section{Climatological input data}

\begin{tabular}{llllllll}
\hline region & $\begin{array}{l}\text { latitude } \\
\left({ }^{\circ} \mathrm{N}\right)\end{array}$ & $\begin{array}{l}\mathrm{M}_{\Theta} \\
\left({ }^{\circ} \mathrm{C}\right)\end{array}$ & $\mathrm{A}_{\Theta}$ & $\begin{array}{l}\mathrm{M}_{\Gamma} \\
(\mathrm{K} / 100 \mathrm{~m})\end{array}$ & $\mathrm{A}_{\Gamma}$ & $\mathrm{n}$ & $\begin{array}{l}\mathrm{P} \\
(\mathrm{m} / \mathrm{yr} ; \mathrm{h} \mathrm{in} \mathrm{m})\end{array}$ \\
\hline $1(40 \%)$ & 76 & -10 & 14 & 0.65 & 0.25 & 0.3 & $0.25 \exp (-\mathrm{h} / 8000)$ \\
$2(25 \%)$ & 65 & -1 & 9 & 0.65 & 0.25 & 0.7 & $0.86 \exp (-\mathrm{h} / 3000)$ \\
$3(15 \%)$ & 67 & -6 & 14 & 0.775 & 0.125 & 0.4 & $0.16+0.00007 \mathrm{~h}$ \\
$4(20 \%)$ & 75 & -9 & 17 & 0.75 & 0.15 & 0.5 & $0.21+0.00021 \mathrm{~h}-5.1 \times 10^{-8} \mathrm{~h}^{2}$ \\
\hline
\end{tabular}

